Dokuz Eylül Üniversitesi-Mühendislik Fakültesi

Fen ve Mühendislik Dergisi

Cilt 20, Sayı 60, Eylül, 2018
Dokuz Eylul University-Faculty of Engineering Journal of Science and Engineering Volume 20, Issue 60, September, 2018

\title{
Biyolojik Çamurların Elektro-Oksidasyon Prosesi ile Şartlandırılması
}

\author{
Gülbin ERDEN \\ Pamukkale Üniversitesi, Mühendislik Fakültesi, Çevre Mühendisliği Bölümü, 20070, Denizli \\ (ORCID: 0000-0001-5719-1950)
}

(Alınış / Received: 27.03.2018, Kabul / Accepted: 17.05.2018, Online Yayınlanma / Published Online: 15.09.2018)

Anahtar Kelimeler Özet: Bu çalışmada bir ileri oksidasyon yöntemi olan elektroBiyolojik Çamur, Elektrooksidasyon Filtrelenebilirlik, Yanıt Yüzey Metodu oksidasyon prosesinin evsel nitelikli arıtma çamurlarını su verme özelliklerini geliștiren bir șartlandırma yöntemi olarak uygulanabilirliği değerlendirilmiștir. Elektro-oksidasyon prosesi, Denizli'de bulunan bir evsel atıksu arıtma tesisinden alınan biyolojik çamurlara uygulanmıștır. Şartlandırma açısından en uygun proses koşullarının belirlenmesine yönelik olarak Yanıt Yüzey İstatistiksel Deney Metodu kullanılmıştır. Kapiler emme süresi (KES) değerindeki azalma yüzdesi (ЕкЕS) sistem verimi olarak dikkate alınmıș; değișken parametreler ise uygulanan gerilim ve süre olarak seçilmiştir. Kapiler emme süresinde en yüksek azalma yüzdesi 30 volt gerilimin 20 dakika süre ile uygulaması ile elde edilmiș olup, bu uygulamada EKES değeri \%30,5 olarak belirlenmiștir. Elektrolit ilavesi $\left(15 \mathrm{~g} \mathrm{Na}_{2} \mathrm{SO}_{4} / \mathrm{L}\right)$ çamurun su verme özelliklerini geliștirmiștir $\left(\mathrm{E}_{\mathrm{KES}}=\%\right.$ 68). Elektrooksidasyon prosesinin şartlandırma amacıyla kullanılabilirliğini değerlendirmek ve hâlihazırda gerçek ölçekli tesislerde yaygın olarak kullanılan kimyasal şartlandırma işlemi ile karşılaştırma yapabilmek amacıyla çamur örnekleri farklı konsantrasyonlarda katyonik polimer kullanılarak şartlandırma işlemine tabi tutulmuş ve elde edilen sonuçlar elektro-oksidasyon prosesinin iyi bir şartlandırma yöntemi alternatifi olduğunu ortaya koymuştur.

\section{Conditioning of Biological Sludge with Electro-oxidation Process}

\section{Keywords}

Biological Sludge,

Electro-oxidation,

Filterability,

Response Surface

Method
Abstract: In this study, the feasibility of an advanced oxidation method of electro-oxidation process, as a conditioning method for improving the watering properties of domestic sludge was evaluated. Electro-oxidation process was applied biological sludge taken from a wastewater treatment plant in Denzili City. Response Surface Statistical Test Method was used for determination of optimum process conditions in terms of conditioning. While, percent decrease in Capillary Suction Time (CST) value ( $\mathrm{E}_{\mathrm{CST}}$ ) was considered as system respose, applied voltage and time were chosen as variable parameters. Maximum decrase in CST was 
achieved at 30 volt and 20 minutes application and at this application, ECST was determined as $30.5 \%$. Addition of supporting electrolyte $\left(15 \mathrm{~g} \mathrm{Na}_{2} \mathrm{SO}_{4} / \mathrm{L}\right)$ improved dewatering characteristics of sludge $(\mathrm{E} c \mathrm{~s}=68 \%)$. Sludge samples were subjected to conditioning treatment with using different concentrations of cationic polymer in order to evaluate the usability of the electrooxidation process for conditioning purposes and to compare it with the chemical conditioning commonly used process in real scale treatment plants and obtained results showed the electrooxidation process is a good alternative for sludge conditioning.

*Sorumlu yazar: gerden@pau.edu.tr

\section{Giriş}

Mekanik su alma işlemi çamurun nihai bertaraf alanına taşınma maliyetinin azaltılması ve nihai bertaraf ișlemlerinin kolaylaştırılması açısından oldukça önemlidir [1]. Santrifüjleme, belt filtre ve plakalı pres filtre gibi mekanik su alma işlemleri çamur suyunun alınarak çamur hacminin azaltılması amaciyla yaygın olarak kullanılmaktadır [2]. Şartlandırma işlemi mekanik su alma işleminden önce çamurların su verme özelliklerinin geliştirilmesi amacıyla uygulanmakta olup, en yaygın kullanılan şartlandırma işlemi kimyasal şartlandırmadır [3].

Elektro-oksidasyon yönteminin atıksu arıtımında kullanımına yönelik çalışmalar olmakla birlikte [4], yöntemin çamur şartlandırma amacıyla kullanımı oldukça yeni bir konudur. Yapılan literatür taramasına göre ulaşılabilen kaynaklar dikkate alındığında, elektro-oksidasyon ile çamur ön arıtımına yönelik olarak yapılan çalışmalar oldukça sınırlıdır. Literatürde karşımıza çıkan bir çalışmada $\quad \mathrm{Ti} / \mathrm{RuO}_{2} \quad$ elektrodunun kullanıldığı elektro-oksidasyon uygulamasının kentsel nitelikli arıtma çamurlarının filtrelenebilirlik özellikleri üzerindeki etkisi incelenmiştir. Çalışmada 21 volt ve 12 dakika uygulama süresi ile kapiler emme süresinin $\% 18,8$ oranında azaldığı, elektro-oksidasyon yönteminin arıtma çamurunun filtrelenebilirlik özelliğini arttırdığı belirlenmiştir [5]. Benzer bir çalışmada $\mathrm{Ti} / \mathrm{RuO}_{2}$ kulanılarak 50 volt ve 5 dakika sureyle elektro-oksidasyon uygulamasının çamurların su vermesi açısından en uygun sistem koşulları olduğu KES parametresi dikkate alınarak belirlenmiş ve bu uygulama ile polielektrolit kullanımının \%50 oranında azaltılabileceği belirtilmiştir [6]. Elektro-oksidasyon prosesi paslanmaz çelik, titanyum gibi inert elektrotların kullanımı ile doğrudan anodik oksidasyon ve dolaylı oksidasyon prosesleri ile yürütülmektedir. Doğrudan anodik oksidasyon prosesinde, organik maddeler anot yüzeyine adsorplanmakta ve sonra anodik elektron transfer reaksiyonu bu maddeleri parçalamaktadır. Elektrokimyasal reaksiyonlar hipoklorit, hidrojen peroksit gibi güçlü oksitleyicileri oluşturabilmektedir [7]. Destekleyici elektrolit ilavesi bazı kimyasal oksitleyicileri oluşturmakta ve oksidasyonun gelişmesinde önemli rol oynayabilmektedir. Örneğin, $\mathrm{Na}_{2} \mathrm{SO}_{4}$ elektroliti ilavesi sülfat radikali $\left(\mathrm{SO}_{4}{ }^{*}\right)$ oluşumuna neden olmaktadır [8]. Proses, mekanizması itibarı ile çamur hücrelerinin parçalanmasına neden olmaktadır. Yöntemin hücre parçalanmasına neden olması çamur üst suyu özelliklerini etkileyeceğinden, elektro-oksidasyon işleminin çamur üst suyu özellikleri üzerine etkisinin 
belirlenmiş olması da çalışmanın özgünlüğü açısından önemlidir. Yürütülen bu çalışmada anot olarak titanyum elektrot, katot olarak ise paslanmaz çelik elektrotlar kullanılmıştır. Ayrıca, elektrolit ilavesinin çamurların su verme özellikleri üzerine etkisi de araştırılmıştır. Çalışmada ayrıca, elektro-oksidasyon prosesinin şartlandırma amacıyla kullanılabilirliğini değerlendirmek ve hâlihazırda gerçek ölçekli tesislerde yaygin olarak kullanılan kimyasal şartlandırma işlemi ile karşılaştırma yapabilmek amacılya çamur örnekleri katyonik polimer ile şartlandırma işlemine tabi tutulmuştur.

\section{Materyal ve Metot}

\section{1. Çamur Özellikleri}

Deneysel çalışmalarının yürütülmesi sırasında kullanılan arıtma çamuru örnekleri için Denizli Belediyesi'ne ait Evsel Atıksu Arıtma Tesisi'nin son çökeltim havuzu geri devir hattından alınmıştır. Ham çamur özellikleri Tablo 1 'de verilmiştir.

Tablo 1. Ham çamur özellikleri

\begin{tabular}{lc}
\hline Parametre & Değer \\
\hline $\mathrm{pH}$ & 7 \\
\hline $\begin{array}{l}\text { Elektriksel İletkenlik, EI } \\
(\mu \mathrm{mho} / \mathrm{cm})\end{array}$ & 2540 \\
\hline $\begin{array}{l}\text { Kuru Madde İçeriği, KM } \\
(\%)\end{array}$ & 2,2 \\
\hline $\begin{array}{l}\text { Organik Madde İçeriği, OM } \\
(\%)\end{array}$ & 59,10 \\
\hline $\begin{array}{l}\text { Askıda Katı Madde İçeriği, } \\
\text { AKM (mg/L) }\end{array}$ & 17700 \\
\hline $\begin{array}{l}\text { Uçucu Askıda Katı Madde } \\
\text { Iç̧eriği, UAKM (mg/L) }\end{array}$ & 14690 \\
\hline
\end{tabular}

Çamur özelliklerini belirlemeye yönelik tüm parametreler Standart Metotlarda verilen prosedüre uygun olarak analizlenmiştir [9]. Şartlandırma işlemi sonrasinda çamur üst suyu özelliklerinin belirlenmesine yönelik olarak analizler yapılmış olup, çamur üst suyu çamur örneklerinin 15 dakika boyunca 3000 devir/dakika hızda santrifüjlenmesi ile elde edilmiştir.

\subsection{Elektro-oksidasyon Prosesi}

Çalışmada kullanılan elektrooksidasyon düzeneği, $0-30$ volt aralığında çalışabilen bir DC güc kaynağı, bir elektrot çifti, bir karıştırıcı tabladan oluşmaktadır. $500 \mathrm{~mL}$ çamur örneği $1 \mathrm{~L}$ hacminde behere konulmuş, manyetik karıştırıcı ile çamur homojenliği sağlanmıştır. Boyutları $10 \mathrm{mmX} 10 \mathrm{mmX} 0.5 \mathrm{~mm}$ olan titanyum plakalar beher içerisine karşıllıklı olarak yerleștirilmiș ve titanyum elektrotlar hem anot hem de katot olarak kullanılmıştır.

\subsection{Kimyasal Şartlandırma Yöntemi}

Ham çamur örnekleri, Tablo 2' de özellikleri verilen katyonik özellikte polimer kullanılarak şartlandırılmıştır. Şartlandırma çalışmalarında klasik jar testi metodu kullanılmıştır. \%0,5' lik polimer çözeltisi ve $500 \mathrm{~mL}$ çamur hacmi ile çalışılmıştır.

Tablo 2. Kullanılan polimerin özellikleri

\begin{tabular}{ll}
\hline Parametre & Özellik \\
\hline Tipi & Katyonik \\
\hline Görünüş & Beyaz \\
\hline Yoğunluk & $0.70 \mathrm{~g} / \mathrm{cm}^{3}$ \\
\hline Partikül Boyutu & $\% 98<1750 \propto \mathrm{cm}$ \\
\hline Molekül Ağırlığı & Çok Yüksek \\
\hline
\end{tabular}

1- $10 \mathrm{~g} / \mathrm{kg}$ aralığında değișen konsantrasyonlarda polimer çamur örneklerine ilave edilmiş; örnekler 1 dakika süreyle 200 devir/dakika hızda; 30 dakika süreyle 25 devir/dakika hızda karıştırılarak şartlandırma sağlanmıştır.

\subsection{Deney Koşullarının Belirlenmesi}

Yürütülen çalışmada elektro-oksidasyon prosesi için en uygun proses koşullarının belirlenmesi amacıyla bir Yanıt Yüzey İstatistiksel Deney Metodu olan Merkez Kompozit Tasarımı 
kullanılmıştır. İstatistiksel model iki değişken parametre (gerilim ve süre) üzerine kurulmuş olup; KES değerindeki azalma yüzdesi (ЕкеS) sistem verimi olarak dikkate alınmıștır. KES değerinde en fazla azalmaya olanak veren elektrooksidasyon uygulaması sonrasinda elektrolit konsantrasyonunun prosese olan etkisinin belirlenmesi hedeflenmiştir. Elektro-oksidasyon prosesi için belirlenen değişken parametreler olan gerilim 1 - 30 volt aralığında, süre ise $1-60$ dakika aralığında uygulanmıștır. Model "Design Expert 7" programının kullanılmasıyla oluşturulmuştur. Yanıt Yüzey İstatiktiksel Deney Modeli'ne göre kullanılan bağıntı aşağıdaki gibi verilmektedir:

$$
\begin{aligned}
\mathrm{E}=\mathrm{b}_{0} & +\mathrm{b}_{1} \mathrm{X}_{1}+\mathrm{b}_{2} \mathrm{X}_{2}+\mathrm{b}_{12} \mathrm{X}_{1} \mathrm{X}_{2} \\
& +\mathrm{b}_{11} \mathrm{X}_{12}+\mathrm{b}_{22} \mathrm{X}_{22}
\end{aligned}
$$

$\mathrm{Bu}$ bağıntıda, $\mathrm{E}$ : beklenen verim, $\mathrm{X}_{1}, \mathrm{X}_{2}$ : değişken parametreler (sırasılyla volt ve süre), $b_{0}$ : sabit $b_{1}$ ve $b_{2}$ : lineer sabitler, $b_{12}$ ve $b_{13}$ : çapraz ürün sabitleri, $b_{11}$ ve $b_{22}$ : ikinci dereceden sabitler olarak verilmektedir.

Tablo 3. Yanıt Yüzey Metoduna Göre Belirlenen Deney Noktaları

\begin{tabular}{ccc}
\hline No & $\begin{array}{c}\text { Deney } \\
\text { kodları }\end{array}$ & Deney noktaları
\end{tabular}

\begin{tabular}{ccccc}
\hline & $\mathrm{X}_{1}$ & $\mathrm{X}_{2}$ & $\begin{array}{c}\text { Gerilim } \\
\text { (volt) }\end{array}$ & $\begin{array}{c}\text { Süre } \\
\text { (dakika) }\end{array}$ \\
\hline 1 & $-\mathrm{k}$ & 0 & 1 & 30,5 \\
\hline 2 & $+\mathrm{k}$ & 0 & 30 & 30,5 \\
\hline 3 & 0 & 0 & 15,5 & 30,5 \\
\hline 4 & +1 & +1 & 25,8 & 51,4 \\
\hline 5 & 0 & 0 & 15,5 & 30,5 \\
\hline 6 & 0 & 0 & 15,5 & 30,5 \\
\hline 7 & -1 & +1 & 5,3 & 51,4 \\
\hline 8 & -1 & -1 & 5,3 & 9,6 \\
\hline 9 & 0 & $+\mathrm{k}$ & 15,5 & 60 \\
\hline 10 & 0 & 0 & 15,5 & 30,5 \\
\hline 11 & 0 & 0 & 15,5 & 30,5 \\
\hline 12 & 0 & $-\mathrm{k}$ & 15,5 & 1 \\
\hline 13 & +1 & -1 & 25,8 & 9,6 \\
\hline
\end{tabular}

Merkezi Kompozit Tasarım'da her bir parametrenin beş düzeyi vardır. Bunlar +1 ve -1 ile ifade edilen faktöriyel noktalar $+\mathrm{k}$ ve $-\mathrm{k}$ ile ifade edilen eksenel noktalar, 0 olarak ifade edilen merkez noktalardır. Faktöriyel noktalar, bir faktörün en yüksek (+1) ve en düşük (1) düzeylerinden olușur. Eksenel noktalar, faktöriyel noktaların noktaların daha ötesinde olan ve program tarafından belirlenen değerlerdir. Seçilen aralıklara (sınır değerlere) göre belirlenen deney noktaları Tablo 3'de verilmektedir. Yanıt yüzey metodu 2 değişken parametre için 13 adet deney noktası önermektedir.

\section{Bulgular}

Değişkenlerin kombine etkileri varyans analizi (ANOVA) ile değerlendirilmiş olup, sonuçlar Tablo 4'de verilmiştir. göstermiștir.

\begin{tabular}{|c|c|c|c|}
\hline Kaynak & $\begin{array}{l}\text { Ortalama } \\
\text { Kare }\end{array}$ & $\begin{array}{l}\text { F- } \\
\text { Değer }\end{array}$ & $\begin{array}{l}\text { p- } \\
\text { Değer }\end{array}$ \\
\hline Model & 60,07 & $\begin{array}{l}109,2 \\
1\end{array}$ & $<0,0001$ \\
\hline Artık & 0,55 & & \\
\hline $\mathrm{R}^{2}$ & 0,9873 & & \\
\hline $\begin{array}{l}\text { Ayarlanmış } \\
\mathrm{R}^{2}\end{array}$ & 0,9783 & & \\
\hline $\begin{array}{l}\text { Yeterli } \\
\text { hassasiyet }\end{array}$ & 36,847 & & \\
\hline
\end{tabular}

Tablo 4. ANOVA Tablosu

Elde edilen regresyon katsayısı $\left(\mathrm{R}^{2}\right)$ değeri, veri noktalarının modele ne kadar uyduğunu göstermektedir. Düzeltilmiş $\mathrm{R}^{2}$ ise veri noktalarının modele uygunluğunu gösterirken modeldeki sınır değerler içerisinde kalmaktadır [10]. Bu nedenle modelin değerlendirilmesinde düzeltilmiș $\mathrm{R}^{2}$ değeri dikkate alınmış olup, belirlenen düzeltilmiş $\mathrm{R}^{2}$ değeri $(\% 97,8)$, bu çalıșmadaki modelin deney verilerine tatmin edici bir şekilde uygun olduğunu göstermiştir. Elde edilmiş olan F-değeri modelin istatistiksel olarak önemli olduğunu, p-değeri $\quad(<0,0001)$ ise 
modelin $\% 5$ güven aralığında kaldığını göstermiştir. Modelden beklenen verimler ve deneyler sonucunda elde edilen verimler Tablo 5'de gösterilmektedir. Gözlenen ve beklenen verimlerin çok yakın değerler olması, modelin verim için de uygun olduğunu göstermektedir.

Tablo 5. Deneyler sonucunda gözlenen ve yanıt yüzey deney modelinde beklenen verimler

\begin{tabular}{ccc}
\hline \multicolumn{2}{c}{ EKes (\%) } \\
\hline No & $\begin{array}{c}\text { Gözlenen } \\
\text { Verim }\end{array}$ & $\begin{array}{c}\text { Beklenen } \\
\text { Verim }\end{array}$ \\
\hline 1 & 21,3 & 21,3 \\
\hline 2 & 30,7 & 30,8 \\
\hline 3 & 21,8 & 22,1 \\
\hline 4 & 21,6 & 21,5 \\
\hline 5 & 21,9 & 22,1 \\
\hline 6 & 22,0 & 22,1 \\
\hline 7 & 21,9 & 21,4 \\
\hline 8 & 11,2 & 11,9 \\
\hline 9 & 15,1 & 16,0 \\
\hline 10 & 22,0 & 22,1 \\
\hline 11 & 22,1 & 22,1 \\
\hline 12 & 12,9 & 11,9 \\
\hline 13 & 24,0 & 25,2 \\
\hline
\end{tabular}

KES testi çamurun filtrelenebilirlik özelliğini değerlendiren basit ve çabuk sonuç veren bir testtir. Aritma çamurlarının su verme kapasitesi hakkında fikir vermekle birlikte kayma gerilmelerinin ihmal edildiği bir test olduğu için çamurların farklı mekanik su alma işlemlerindeki performanslarını değerlendirmek amacıyla kullanılamaz [11]. Şekil 1' de farklı gerilim uygulamalarında, artan süreye bağlı EKES değişimi gösterilmiștir. Artan elektriksel gerilim çamurun filtrelenebilirlik özelliğini arttırmıştır. Kapiler emme süresinde en yüksek azalma verimi 30 volt gerilim uygulamasinda elde edilmiştir. Süreye bağlı olarak EKES değerleri incelendiğinde, 20 dakika uygulamasında elde edilen EKEs değeri $(\% 30,5)$ ve 30 dakika uygulamasında elde edilen EKES değeri $(\% 30,8)$ 'nin çok yakın olduğu göz önüne alınarak en uygun koşulların 30 volt gerilim uygulaması ve 20 dakika uygulama süresi olduğuna karar verilmiștir.

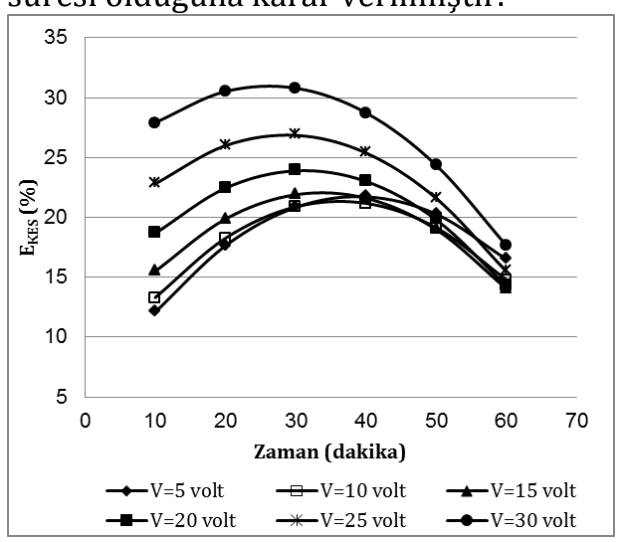

Şekil 1. Farklı gerilim uygulamalarında artan süreye bağlı EKEs değişimi

Elektrolit ilavesinin çamurun filtrelenebilirlik özelliklerine etkisini belirlemek için en uygun proses koşulu $(30 \mathrm{~V}+20 \mathrm{dk})$ uygulaması öncesinde $1-30$ $\mathrm{g} / \mathrm{L}$ aralı̆̆ında değișen farklı konsantrasyonlarda $\mathrm{Na}_{2} \mathrm{SO}_{4}$ ilavesi sonrasında EKES değerleri belirlenmiştir. Sonuçlar Şekil 2' de özetlenmiştir.

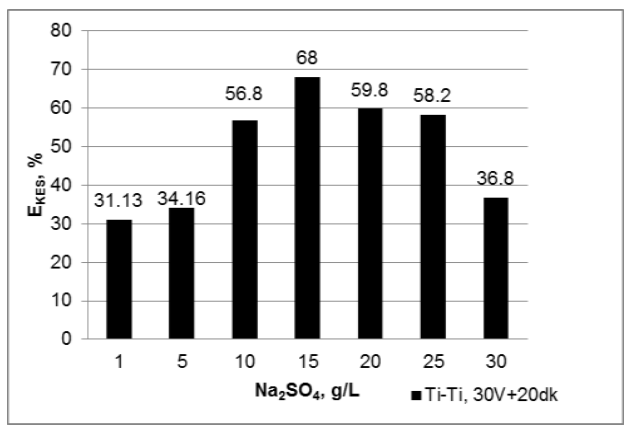

Şekil 2. Elektrolit ilavesinin EKES üzerine etkisi

Elektrolit ilavesi çamurların fiziksel özelliklerini geliştirmiş ve en yüksek EKES değeri $15 \mathrm{~g} / \mathrm{L} \mathrm{Na}_{2} \mathrm{SO}_{4}$ ilavesi ile elde edilmiştir. $\mathrm{Bu}$ uygulamada KES değerinin ham çamura oranla \%68 oranında azaldığı belirlenmiştir. 
Gerçek ölçekli arıtma tesislerinde en yaygın olarak kullanılan şartlandırma yöntemi katyonik polimer kullanımıyla yürütülen kimyasal şartlandırmadır. Elektro-oksidasyon yönteminin çamur şartlandırma amaciyla kullanılabilirliğinin değerlendirilmesi ve hâlihazırda yaygın olarak kullanılan kimyasal şartlandırma verimi ile karşılaştırma yapabilmek amacıyla çamur örnekleri katyonik polimer ile şartlandırma işlemine tabi tutulmuştur. Çamur örnekleri 1-30 g/ kg Kuru Madde (KM) arasında değișen dozlarda katyonik polimer ilavesi ile şartlandırılmış ve elde edilen KES değerleri Şekil 3' de verilmiştir.

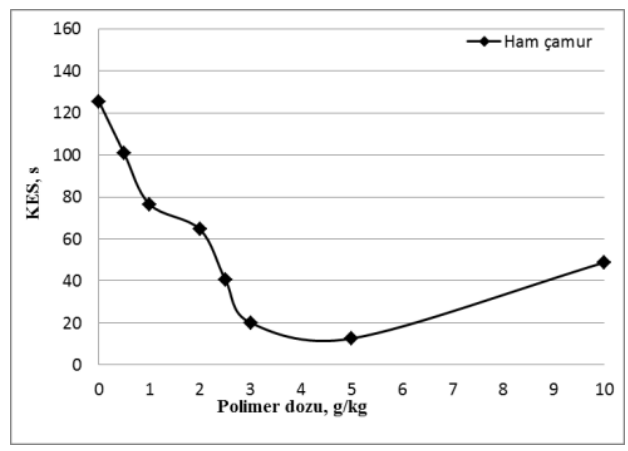

Şekil 3. Katyonik polimer ile şartlandırma sonrası KES değişimi

Sonuçlar incelendiğinde en uygun doz aralığının $3-5 \mathrm{~g} / \mathrm{kg} \mathrm{KM}$ olduğu sonucuna varılmıștır. $\mathrm{Bu} \quad \mathrm{doz}$ uygulamalarında KES değerleri sırasıyla, $20,1 \mathrm{~s}$ ve $12,6 \mathrm{~s}$ olarak belirlenmiștir. Elektrolit ilavesi (15 g /L $\mathrm{Na}_{2} \mathrm{SO}_{4}$ ) sonrasinda elektro-oksidasyon uygulaması $\quad(30 \mathrm{~V}+20 \mathrm{dk}), \quad \% 68$ oranında KES azalması sağlamış ve bu uygulamada KES değeri 40,13 s olarak belirlenmiştir. Elektro-oksidasyon uygulaması ile daha yüksek bir KES değeri elde edilmiş olmakla birlikte, her iki uygulamadan elde edilen KES değerleri oldukça düşük değerler olup, uygulamaların çamurların filtrelenebilme özelliklerini geliştirdiği görülmektedir. $\mathrm{Bu}$ sonuç, elektrooksidasyon prosesinin çamur şartlandırma amacıyla kullanılabilecek bir alternatif olduğunu ortaya koymuştur.

Elektro-oksidasyon prosesi doğrudan anodik oksidasyon ve dolaylı oksidasyon prosesleri ile yürütülmektedir [7]. Elektrooksidasyon prosesi bir ileri oksidasyon prosesi olduğu için dolaylı ve doğrudan oksidasyona bağlı mekanizmalar ile çamur içeriğindeki hücrelerin dezentegrasyonu gerçekleşebilir. Dezentegrasyon işlemi, organik çamur bileşenlerinin çamur sıvı fazına geçmesine sebep olmaktadır [12]. Elektro-oksidasyon uygulaması sonrasında çamur üst suyu özelliklerinin değişimini belirlemek amaciyla ham çamur üst suyu ve elektro-oksidasyon işlemi uygulanmış çamur suyunda analizler yapılmış ve analiz suçları Tablo 6' da gösterilmiştir. Elde edilen sonuçlar, elektrooksidasyon işleminin çamur üst suyunda KOİ, toplam azot ve toplam fosfor konsantrasyonlarında artışa sebep olduğu görülmektedir.

Tablo 6. Elektro-oksidasyon uygulaması sonrasında çamur üst suyu özellikleri

\begin{tabular}{lcc}
\hline & $\begin{array}{c}\text { Ham } \\
\text { Çamur }\end{array}$ & $\begin{array}{c}\text { Elektro- } \\
\text { oksidasyon } \\
\text { sonrası çamur }\end{array}$ \\
\hline KOİ (mg/L) & 1295 & 3675 \\
\hline $\begin{array}{l}\text { Toplam } \\
\text { azot } \\
\text { (mg/L) }\end{array}$ & 44,2 & 112,2 \\
\hline $\begin{array}{l}\text { Toplam } \\
\text { fosfor } \\
\text { (mg/L) }\end{array}$ & 18,6 & 35,4 \\
\hline
\end{tabular}

Elektro-oksidasyon uygulaması sonrasinda çamur üst suyunda KOİ, toplam azot ve toplam fosfor konsantrasyonları artmıştır. Çamur üst suyundaki KOİ, toplam azot ve toplam fosfor konsantrasyonları artışının tesise ilave bir organik yük getireceği göz önüne alınmalıdır. İleri biyolojik arıtma 
yapan tesislerde azot giderimine yönelik olarak uygulanan denitrifikasyon aşaması ilave karbon kaynağı gerektirmektedir. Karbon kaynağı olarak çamur üst suyunun kullanımı dışardan karbon kaynağı almadan bu ilave yükün değerlendirilmesini sağlayabilecektir. Bunun yanı sıra kullanılan elektrolit dolayısıyla çamur üst suyu tuz konsantrasyonu açısından değerlendirilmelidir. Örneğin, literatürde 4-6 g Na+/L (10.9-16.3 g $\left.\mathrm{Na}_{2} \mathrm{SO}_{4} / \mathrm{L}\right) \quad$ konsantrasyon aralığ anaerobik çürüme prosesleri için toksik seviye olarak verilmektedir [13]. Çamur üst suyu debisi, tesise gelen atıksu debisi ile karşılaştırıldığında çok daha düşük olup, tuz konsantrasyonu atıksu debisi ile seyreleceğinden tuz konsantrasyonunun biyolojik arıtma sırasında toksik seviyede olmayacağı görülmektedir.

4. Tartışma ve Sonuç $\mathrm{Bu}$ çalışma sonucunda elektro oksidasyon işleminin evsel nitelikli atıksu arıtma tesisinde oluşan biyolojik çamurların su verme özelliklerini geliştirdiği belirlenmiştir. En uygun proses koşulları 20 dakika süre ile 30 volt gerilim uygulamasında elde edilmiş olup; bu uygulamada KES değeri \%30,5 oranında azalmıştır. Elektro-oksidasyon işleminde elektrolit ilavesinin çamurların filtrelenebilirlik özelliğini geliştirdiği ve $15 \mathrm{~g} \mathrm{Na}_{2} \mathrm{SO}_{4} / \mathrm{L}$ ilavesinin \%68 oranında KES azalmasına neden olduğu tespit edilmiştir. Katyonik polimer ile yürütülen şartlandırma sonuçları, elektro-oksidasyon yöntemi ile elde edilen KES değerlerine oldukça yakın değerler olarak elde edilmiş ve elektro-oksidasyon yönteminin mekanik su alma ișlemleri öncesinde bir şartlandırma yöntemi olarak kullanılabileceği sonucuna varılmıştır
Teşekkür

$\mathrm{Bu}$ çalışma, Türkiye Bilimsel ve Teknolojik Araştırma Kurumu (TUBITAK) tarafindan 112 Y177 nolu proje ile desteklenmiştir.

\section{Kaynaklar}

[1] Gray, N. F. 2005. Water Technology, Sludge Treatment and Disposal. 2nd edition. Butterworth-Heinemann, USA.

[2] Filibeli, A. 2013. Arıtma Çamurlarının İşlenmesi. 7. Baskı. Dokuz Eylül Üniversitesi Mühendislik Fakültesi Yayınları, İzmir.

[3] Tian, X., Trzcinski, A.P., Lin, L.L., $\mathrm{Ng}$, W.J. 2015. Impact of ozone assisted ultrasonication pretreatment on anaerobic digestibility of sewage sludge. Journal of Environmental Science, Cilt. 33, s.29-38.

[4] Chu, Y.Y., Wang, W.J., Wang, M. 2010. Anodic oxidation process for the degradation of 2, 4dichlorophenol in aqueous solution and the enhancement of biodegradability. Journal of Hazardous Material, Cilt. 180(13), s. 247-252.

[5] Yuan, H., Zhu, N., Song, L. 2010. Conditioning of sewage sludge with electrolysis: Effectiveness and optimizing study to improve dewaterability, Bioresource Technology, Cilt. 101 (12), s. 4285-4290.

[6] Yuan, H., Cheng, X., Chen, S., Zhu, N., Zhou, Z. 2011. New sludge pretreatment method to improve dewaterability of waste activated sludge, Bioresource Technology, Cilt. 102 (10), s. 5659-5664.

[7] Chiangi, L.C., Changi, J.E., Wen, T.C. 1995. Indirect Oxidation Effect In Electrochemical Oxidation Treatment of Landfill Leachate. 
Water Research, Cilt. 29(2), s. 671-678.

[8] Kim. S., Choi, S.K., Yoon, B.Y., Lim, S.K., Park, H. 2010. Effects of electrolyte on the electrocatalytic activities of $\mathrm{RuO}_{2} / \mathrm{Ti}$ and $\mathrm{Sb}-$ $\mathrm{SnO}_{2} / \mathrm{Ti}$ anodes for water treatment. Applied Catalysis B: Environment, Cilt. 97(1-2), s. 135-141.

[9] APHA, AWWA, WEF. 2005. Standard Methods for the Examination of Water and Wastewater, 21st edition. American Public Health Association/American Water Works Association/Water Environment Federation, Washington DC, USA.

[10] Parajo, J.C., Alonso, J.L., Lage, M.A., Vazquez, D. 1992. Empirical modeling of Eucalyptus wood processing. Bioprocess Engineering, Cilt. 8, s. 129-136.

[11] Meeten, G.H. and Smeulders, J.B.A.F. 1995. Interpretation of filterability measured by the capillary suction time method. Chemical Engineering Science, Cilt. 50, s. 1273-1279.

[12] Vranitzky, R., Lahnsteiner, J. 2005. Sewage Sludge Disintegration Using Ozone - A Method of Enhancing the Anaerobic Stabilization of Sewage Sludge, VA TECH WABAH, R\&D Process Engineering. Siemensstrasse 89, A-1211 Vienna, Austria.

[13] Speece, R. E. 1996. Anaerobic Biotechnology for Industrial Wastewater, Archae Press, Nashville, TN, USA. 